\title{
Influence of Heating Modes of Compacted Samples from Nickel Powders with Nanosized Particles on Their Interaction with Air
}

\author{
M. I. Alymov ${ }^{a}$, B. S. Seplyarskii ${ }^{a, ~ *, ~ S . ~ G . ~ V a d c h e n k o ~}{ }^{a}$, V. A. Zelensky ${ }^{a}$, N. M. Rubtsov ${ }^{a}$, \\ R. A. Kochetkov ${ }^{a}$, A. S. Shchukin ${ }^{a}$, and I. D. Kovalev ${ }^{a}$ \\ ${ }^{a}$ Merzhanov Institute of Structural Macrokinetics and Problems of Materials Science, Russian Academy of Sciences, \\ Chernogolovka, 142432 Russia \\ *e-mail:seplb1@mail.ru
}

Received September 30, 2020; revised September 30, 2020; accepted October 20, 2020

\begin{abstract}
In this paper, we study compact samples of pyrophoric nickel powders with the average particle size of $85 \mathrm{~nm}$, obtained by the chemical-metallurgical method. For the first time, it is experimentally shown that it is possible to passivate compact samples with a diameter of $3 \mathrm{~mm}$ from pyrophoric nickel powders with nanosized particles in air. For a relative density of 0.4 to 0.5 , the passivation time is only $3-5 \mathrm{~s}$. According to the X-ray phase analysis data, only the Ni phase is observed in passivated samples. It is found that passivated samples retain their thermal stability in air upon slow $(<10 \mathrm{deg} / \mathrm{s})$ heating to $\sim 200^{\circ} \mathrm{C}$, which is an important parameter for fire safety when handling nanopowders. The electron microscopic analysis of the passivated samples did not reveal traces of sintering of nickel nanoparticles, including after checking for thermal stability. The uniform distribution of oxygen over the passivated samples according to the data of energy dispersive analysis (the standard deviation is 0.9 at \%) indicates the volumetric nature of the interaction of the samples with air during passivation. For the obtained passivated samples, the critical heating conditions were determined, under which self-ignition occurs, which is in agreement with N.N. Semyonov's classical theory of thermal explosion.
\end{abstract}

Keywords: nanopowder, compact sample, pyrophoricity, critical condition, thermal ignition, passivation, iron, nickel, air

DOI: $10.1134 / \mathrm{S} 1990793121020135$

\section{INTRODUCTION}

Metal powders, the size of all particles of which is $<100 \mathrm{~nm}$ (nanopowders) are pyrophoric; i.e., they are capable of spontaneously igniting upon contact with air due to their strong chemical activity and large specific surface area [1-4]. In order to make the process of further processing nanopowders into safe products, they are passivated [3-7]. Passivation consists of creating a thin protective film on the surface of nanoparticles, which prevents their spontaneous combustion. Usually passivation lasts tens of hours, which is a limiting factor for the production and use of nanopowders.

The processes of passivation of iron and nickel nanopowders were studied in [8-10]. The totality of our data indicates that for iron and nickel nanopowders, there are critical conditions for thermal ignition related to the change in the ratio between heat release and heat removal. We point out that the presence of a critical ignition condition, when the rate of heat release exceeds the rate of heat removal and a stationary process cannot be attained, was established in the theory of thermal explosion proposed by Acad. N.N. Semenov, which is the base of the modern thermal theory of combustion. This means that the developed theoretical approaches of the classical macroscopic theory of thermal explosion by Semenov [11] are applicable for studying the ignition of macroobjects consisting of nanoparticles [12].

However, it is obvious that there are situations when it is technically impossible or undesirable to passivate the nanopowder, although technical operations with the nanopowder must be carried out. Therefore, the development of methods for producing compact products from nanopowders, allowing us to ensure the required level of safety against fire and explosion in processing both nanopowders and their products is an urgent task.

The published data on the regularities of self-ignition and self-heating of compacted samples from nonpassivated nanopowders are very limited. Thus, in the works $[13,14]$ on the investigation of the ignition of nanosystems with reagent particle sizes of 40 to $80 \mathrm{~nm}$, it was shown that the ignition temperatures and energies can be noticeably lower than in mixtures of ultradispersed powders $(1-100 \mu \mathrm{m})$.

In [15], the features of flame propagation over tablets made from mixtures of $\mathrm{Al} / \mathrm{CuO}$ nanopowders (the so-called nanothermites) were investigated depending on their density during the laser initiation of combus- 
tion. Similar measurements, described in monograph [16], were carried out for samples made of $\mathrm{Al} / \mathrm{MoO}_{3}$ nanopowders, and the results obtained for this nanothermite are qualitatively the same.

This paper presents the results of studying the influence of heating modes of specimens pressed from pyrophoric nickel nanopowders on the features of their interaction with air in order to identify the conditions for the passivation of compact samples. The phase composition and microstructure of the samples after heating, as well as the oxygen distribution over the sample cross section, were measured.

\section{EXPERIMENTAL}

Nickel nanopowder was obtained in the following way: Nickel formate was preliminarily synthesized by the reaction of nickel hydroxide with formic acid. Nickel hydroxide was synthesized by the alkaline treatment of nickel sulfate, precipitation, and drying of the obtained hydroxide. Nickel formate disproportionates at temperatures above $205^{\circ} \mathrm{C}$; at the same time, nickel nanopowder is formed and a gas mixture consisting of carbon dioxide, hydrogen, and water vapor is released [17]. The reactor described in [10], with a filling of nickel formate powder $4 \mathrm{~mm}$ thick ( $15 \mathrm{~g})$, was placed in an oven in a quartz boat and held for $50 \mathrm{~min}$ at a temperature of $209^{\circ} \mathrm{C}$ in an argon flow; then the samples were treated in a stream of hydrogen for $20 \mathrm{~min}$; i.e., the total time spent by the sample in the oven was $70 \mathrm{~min}$. After that, the reactor was taken out of the oven and cooled to $20^{\circ} \mathrm{C}$ in an argon flow. As a result, 4.7-4.8 g of pyrophoric nickel nanopowder was obtained. The average diameter of the nanoparticles, calculated from the specific surface of the powder, was $55 \mathrm{~nm}$. The specific surface area of the Ni nanoparticles was determined by the Brunauer-Emmett-Taylor (BET) method on a Sorbi-M instrument (measurement error of not more than $6 \%$ ).

After preparation, nickel nanopowders were stored in an argon atmosphere of $99.98 \%$ purity in a tightly closed glass bottle. The pyrophoric properties of the powder are retained for $2-3$ days. The vessels with the powder were opened and the samples were pressed in a glove box in an argon atmosphere. The samples were pressed inside a box in an argon atmosphere.

The samples under study were tablets $3.1 \mathrm{~mm}$ in diameter, $2-2.5 \mathrm{~mm}$ in height, and $40-60 \mathrm{mg}$ in weight. The relative density of the samples was $0.4-0.5$ and they were weighed on a GR-202 analytical balance (the measurement error in the range up to $42 \mathrm{~g}$ was $\pm 0.14 \mathrm{mg}$ ). Each of the samples in the box was placed in a separate glass bottle with a ground-in lid. Sample bags were placed in a deep plastic container and removed from the box through an airlock. To exclude the oxidation of the samples, argon was fed into the container with the weighing bottles. Immediately before the experiment, the weighing bottles with compact samples were removed from the plastic container and opened.

The sample was taken out and placed in a boron nitride crucible for 3-5 s. A photograph of a device for heating samples and a diagram of the experiment are shown in Fig. 1. The crucible was heated with a graphite ribbon through which an electric current was passed. The sample lay on a flat thermocouple welded from WRe5/WRe20 wires and rolled to a thickness of $30 \mu \mathrm{m}$. Gaps about $1 \mathrm{~mm}$ wide between the crucible and the lateral and lower surfaces of the sample ensured equal accessibility of the air supply to it. In the experiments, the value of the current through the graphite heater was varied, which led to different values of the heating rate of the sample in the initial section in the range of 16 to $26 \mathrm{~s}$.

The signal from the thermocouples was recorded using a computer. The microstructure of the samples after self-ignition and combustion was investigated by scanning electron microscopy (SEM) using an Ultra Plus microscope produced by Carl Zeiss. The phase composition of the samples was studied using a DRON-3M diffractometer using monochromatic $\mathrm{Cu}\left(K_{\alpha}\right)$-radiation. The diffraction patterns were recorded in a step scan mode in the angle range $2 \theta=20^{\circ}-80^{\circ}$ with a sampling step of $0.2^{\circ}$. The obtained diffraction patterns were analyzed using the PDF-2 database.

\section{RESULTS AND DISCUSSION}

It was shown that if there was no external heating of the sample, then the thermocouple did not register its self-heating. This means that the sample was passivated during the time it was in the air for $\approx 5 \mathrm{~s}$ before being placed on thermocouple 3 (see Fig. 1).

Figure 2 shows thermograms of the heating samples. The average heating rate in the initial section ranged from 7 to $16 \mathrm{deg} / \mathrm{s}$. At heating rates of more than $10 \mathrm{deg} / \mathrm{s}$, starting from a certain temperature, a spontaneous increase in the heating rate (ignition) is observed on the thermograms. The point of intersection of tangents to the areas of thermograms in the self-heating region corresponds to the ignition temperature $T_{c}\left(250-300^{\circ} \mathrm{C}\right)$. At heating rates $<10 \mathrm{deg} / \mathrm{s}$, self-heating was not observed (there is no inflection point on the heating curves), although the samples can be heated to temperatures above $T_{c}$. In this case, a nickel oxide film of sufficient thickness has time to form in the heating section, which prevents the ignition of the sample.

The following experiments were carried out to clarify the effect of the heat release from the chemical oxidation reactions on the heating thermogram at low rates (without ignition). A sample with a height of $2.4 \mathrm{~mm}$ and a diameter of $3 \mathrm{~mm}$, prepared according to the method described in this study, was placed in a crucible 2 (see Fig. 1), it was not removed from it throughout the experiment, and it was not shifted rel- 


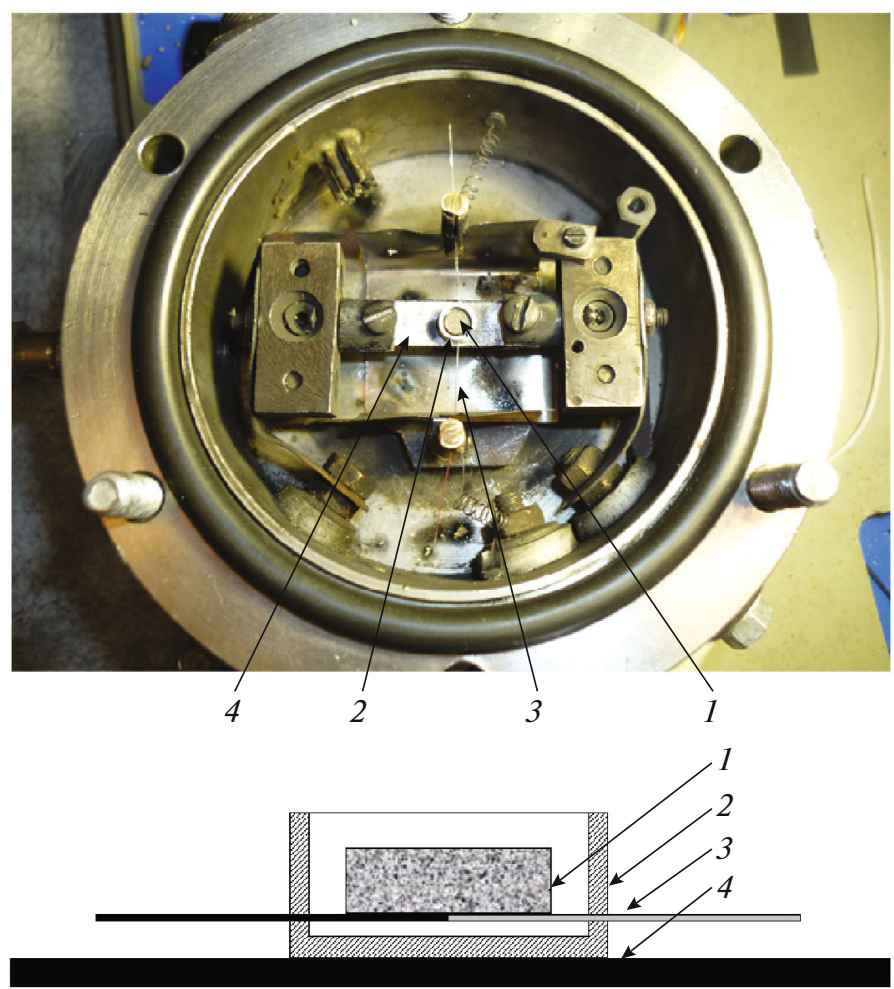

Fig. 1. Experiment scheme: (1) sample, (2) crucible, (3) thermocouple, and (4) graphite heater.

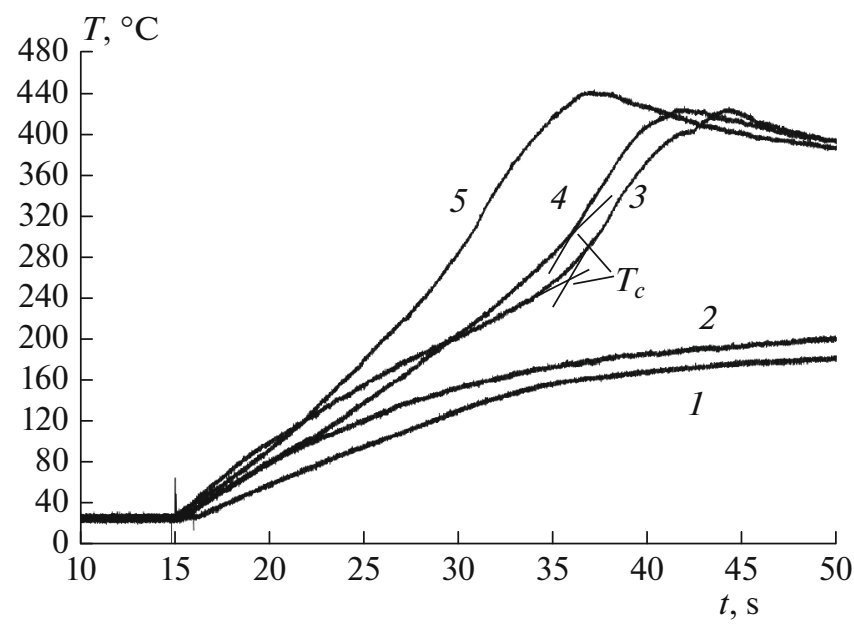

Fig. 2. Thermograms of samples at different average heating rates in the initial section (deg/s): (1) 7, (2) 9, (3) 11 ; (4) 12 , and (5) 16.

ative to the thermocouple. The experiment consisted of three consecutive stages:

1. The sample was heated under conditions that did not lead to its ignition (the heating rate in the initial section was less than $10 \mathrm{deg} / \mathrm{s}$, thermogram 1 in Fig. 3). Then the heating was turned off and the sample was cooled to room temperature.

2. Next, the sample was heated at heating rates leading to its ignition (thermogram 2 in Fig. 3).

3. After completion of the reaction and cooling the sample to room temperature, it was heated again under conditions that coincide with the conditions for recording curve 1 (curve 3 in Fig. 3 ).

The experiments carried out show that during the period of time from removing the samples from the weighing bottles into the air before placing them in the crucible (3-5 s), they are passivated with the retention of chemical activity during high-speed heating. When the initial sample is slowly heated, there is no noticeable heat release due to the nickel oxidation reaction, since the thermograms of the burned (inert) and initial samples coincide. The experiments also showed that compact samples of nickel nanopowder passivated in 


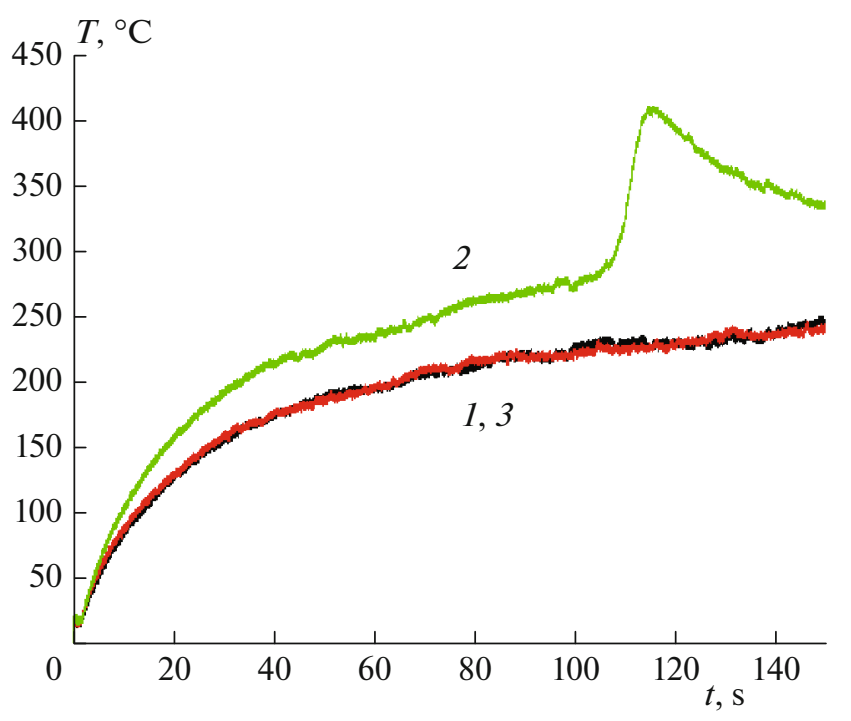

Fig. 3. Thermograms of samples at different average heating rates: (1) $7 \mathrm{deg} / \mathrm{s}$ (original sample), (2) $10 \mathrm{deg} / \mathrm{s}$, and (3) $7 \mathrm{deg} / \mathrm{s}$ (burnt sample).

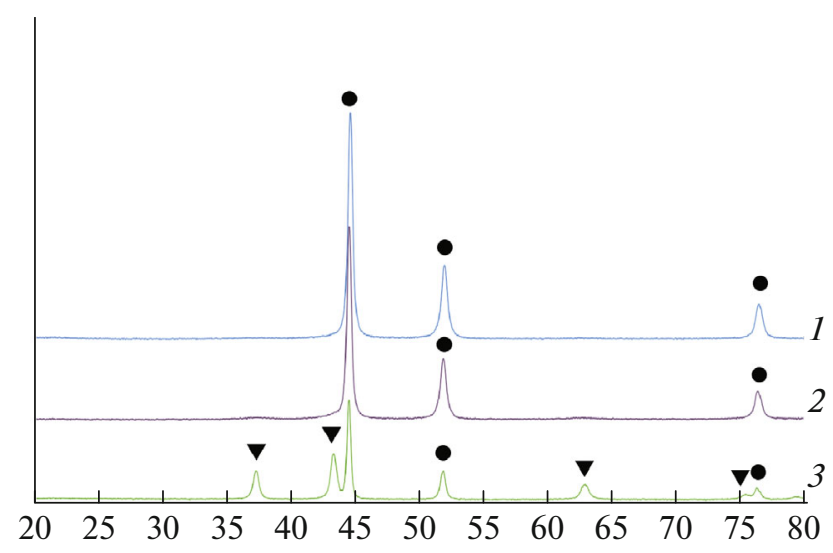

Fig. 4. X-ray phase analysis of passivated compact samples of nickel nanopowder: (1) without additional heating, (2) after slow heating up to $200^{\circ} \mathrm{C}$, and (3) after rapid heating and further self-heating; $\bullet, \mathrm{Ni}$ and $\mathbf{\nabla}, \mathrm{NiO}$.

this way can be stored in air in a wide temperature range without additional oxidation, since their chemical activity will be maintained.

The X-ray phase analysis (XPA) of the initial samples (without heating) and samples after slow heating (ther-

Table 1. Oxygen content in different regions of the samples (at \%) according to EDA data

\begin{tabular}{c|c}
\hline \multicolumn{2}{c}{ Oxygen content } \\
\hline passivated sample & slowly heated sample \\
\hline 6.4 & 11.2 \\
8.5 & 11.7 \\
6.5 & 10.8 \\
6 & 10.7 \\
6.4 & 12.2 \\
- & 14.8 \\
\hline
\end{tabular}

mogram 1 in Fig. 3) showed that no changes in the phase composition occurred (see Fig. 4). Upon rapid heating, leading to the ignition of the samples, the X-ray diffraction patterns of the products of interaction of the samples with air revealed spectra corresponding to the $\mathrm{Ni}$ and $\mathrm{NiO}$ phases (see Fig. 4) in amounts of 60 and $40 \mathrm{wt} \%$, respectively (corundum number method).

Based on the results of the work $[9,10]$, it could be expected that the process of interaction of the sample with air will be of a surface nature, and the unreacted material will remain in the inner layers of the sample. To verify this assumption, the microstructures of a transverse fracture of a cylindrical sample after passivation and slow heating-cooling were analyzed by SEM. Figure 5 shows photographs of specimen fractures taken with different magnifications. The photographs taken with a small magnification show that the structure of the samples near the outer surface is uniform. These results indicate the volumetric nature of the passivation process. The photographs of the fractures of the samples taken at high magnification show the accumulation of nickel nanoparticles of 50 to $100 \mathrm{~nm}$, which is consistent with the data of [9].

The integral energy dispersive analysis (EDA) showed an almost uniform distribution of the elements (oxygen and nickel) over the fracture surface of both passivated and slowly heated samples (Table 1). When analyzing the experimental EDA data, one should take into account the fact that the transverse fracture of the sample was analyzed, and not the thin section. Therefore, the EDA results are of a qualitative rather than quantitative nature and only give an idea of the ratio of the oxygen content in different regions of the sample's fracture and in different samples.

The average oxygen content on the fracture surface of both passivated and slowly heated samples is approximately 7 and 12 at \%, respectively. The standard deviation $S=\left[\sum_{n}(x-\bar{x})^{2} / n\right]^{1 / 2}$ is 0.9 and 1.4 at $\%$, respectively, which is much less than the average oxygen content on the fracture surface. The increase in the oxygen content in a slowly heated sample confirms our hypothesis, expressed at the beginning of the article, that during slow heating, a nickel oxide film of sufficient thickness is formed in the heating section, which prevents the ignition of the sample. However, upon repeated rapid heating, ignition occurs, which indicates an insignificant thickness of the protective layer after slow heating.

\section{CONCLUSIONS}

1. The conditions of passivation for $3-5 \mathrm{~s}$ for compact samples $3 \mathrm{~mm}$ in diameter made of pyrophoric nickel nanopowder with a relative density of 0.4 to 0.5 were established.

2. The critical heating conditions were determined that separate the processes with ignition (rapid heating) and without ignition. 


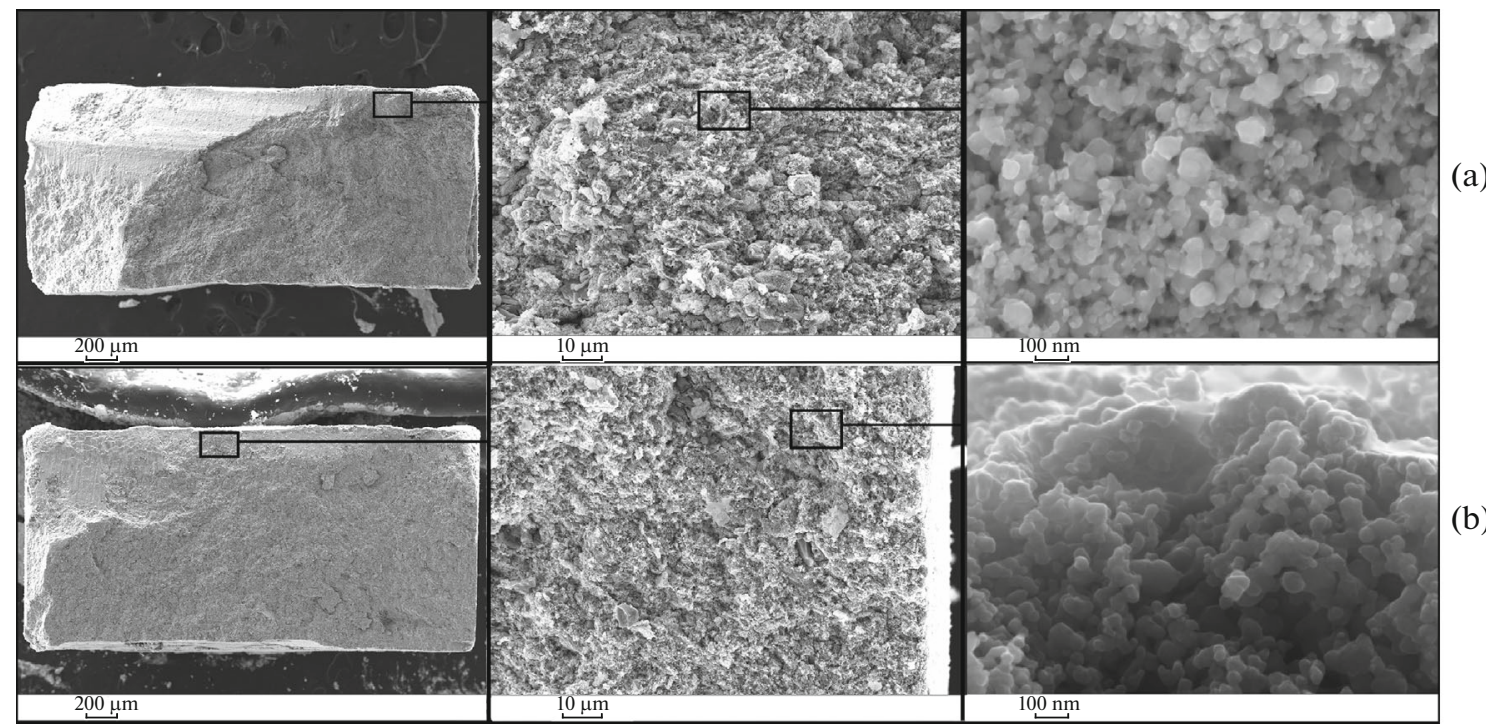

Fig. 5. Microstructure of transverse fracture of samples with different magnification: (a) passivated, (b) slowly heated.

3. It was found that when the initial sample is slowly heated, no noticeable heat release occurs due to the nickel oxidation reaction.

4. It was shown that only the Ni phase is present in the XRD spectra of passivated samples, which indicates an insignificant content of the oxide phases $(<5 \%)$ after passivation.

5. The integral energy dispersive analysis showed an almost uniform distribution of the elements (oxygen and nickel) over the fracture surface of both passivated and slowly heated samples, which may indicate the volumetric nature of the interaction of the samples with air.

\section{FUNDING}

The study was supported by a grant from the Russian Science Foundation (project no. 16-13-00013P).

\section{OPEN ACCESS}

This article is licensed under a Creative Commons Attribution 4.0 International License, which permits use, sharing, adaptation, distribution and reproduction in any medium or format, as long as you give appropriate credit to the original author(s) and the source, provide a link to the Creative Commons license, and indicate if changes were made. The images or other third party material in this article are included in the article's Creative Commons license, unless indicated otherwise in a credit line to the material. If material is not included in the article's Creative Commons license and your intended use is not permitted by statutory regulation or exceeds the permitted use, you will need to obtain permission directly from the copyright holder. To view a copy of this license, visit http://creativecommons.org/licenses/by/4.0/.

\section{REFERENCES}

1. J. Bouillard, A. Vignes, O. Dufaud, L. Perrin, and D. Thomas, France J. Hazard. Mater 181, 873 (2010).
2. A. Pivkina, P. Ulyanova, Y. Frolov, S. Zavyalov, and J. Schoonman, Propell., Explos., Pyrotech. 29 (1), 39 (2004).

3. Nanoparticle Technology Handbook, Ed. by M. Hosokawa, K. Nogi, M. Naito, and T. Yokoyama (Elsevier, Amsterdam, 2007).

4. N. M. Rubtsov, B. S. Seplyarskii, and M. I. Alymov, Ignition and Wave Processes in Combustion of Solids (Springer Int., New York, 2017).

5. M. Flannery, T. G. Desai, T. Matsoukas, S. Lotfizadeh, and M. A. Oehlschlaeger, J. Nanomater. 2015, 185 (2008).

6. M. J. Meziani, C. E. Bunker, F. Lu, et al., ACS Appl. Mater. Interfaces 1, 703 (2009).

7. R. Nagarajan and T. A. Hatton, Nanoparticles: Synthesis, Stabilization, Passivation, and Functionalization, ACS Symp. Ser. (Am. Chem. Soc., Washington DC, 2008).

8. M. I. Alymov, N. M. Rubtsov, B. S. Seplyarskii, V. A. Zelensky, A. B. Ankudinov, I. D. Kovalev, R. A. Kochetkov, A. S. Shchukin, E. V. Petrov, and N. A. Kochetov, Dokl. Chem. 484, 19 (2019). https://doi.org/10.31857/S0869-5652484148-51

9. M. I. Alymov, N. M. Rubtsov, B. S. Seplyarskii, et al., Mendeleev Commun. 27, 631 (2017). https://doi.org/10.1016/j.mencom.2017.11.032

10. M. I. Alymov, N. M. Rubtsov, B. S. Seplyarskii, V. A. Zelensky, and A. B. Ankudinov, Mendeleev Commun. 27 (5), 482 (2017).

https://doi.org/10.1016/j.mencom.2017.09.017

11. N. N. Semenov, On Some Problems of Chemical Kinetics and Reactivity (Akad. Nauk SSSR, Moscow, 1958; Elsevier, Amsterdam, 1958).

12. B. S. Seplyarskii, T. P. Ivleva, and M. I. Alymov, Dokl. Phys. Chem. 478, 23 (2018).

13. S. Dong, H. Cheng, H. Yang, P. Hou, and G. Zou, J. Phys.: Condens. Matter 14, 11023 (2002).

14. E. M. Hunt and M. L. Pantoya, J. Appl. Phys. 98, 034909 (2005).

15. F. Saceleanu, M. Idir, N. Chaumeix, and J. Z. Wen, Front. Chem. 6, 465 (2018). https://doi.org/10.3389/fchem.2018.00465

16. A. A. Gromov and U. Teipel, Metal Nanopowders: Production, Characterization, and Energetic Applications (Wiley, New York, 2014).

17. J. G. Dean, Ind. Eng. Chem. Soc. 44, 985 (1952). 